\title{
PROMOÇÃo dA SEGURANÇA NA CRIANÇA
}

\author{
Celeste Antão \\ Instituto Politécnico de Bragança \\ UICISA: E da Escola Superior de Saúde do IPB \\ celeste@ipb.pt \\ Zélia Caçador Anastácio \\ CIEC, Instituto de Educação da Universidade do Minho \\ zeliaf@ie.uminho.pt \\ Eugénia Anes \\ Instituto Politécnico de Bragança \\ UICISA: E da Escola Superior de Saúde do IPB \\ eugenia@ipb.pt
}

Fecha de Recepción: 1 Mayo 2019

Fecha de Admisión: 25 Septiembre 2019

\section{RESUMO}

A segurança das crianças em geral e a prevenção de acidentes em particular é responsabilidade de todos. É importante desenvolver uma cultura de segurança no sentido de minimizar os riscos aos quais as crianças estão expostas. Com este trabalho pretende-se refletir, por um lado, sobre uma problemática atual que conduz a um elevado número de anos de vida perdidos, bem como à redução da qualidade de vida de muitas crianças e dos seus familiares. Por outro lado pretende-se fazer uma análise reflexiva dos acidentes não intencionais como causa de sofrimento, deficiência e incapacidade. A metodologia adotada foi de natureza qualitativa, tendo se procedido a uma recolha de documentos fornecedores de dados relativos à problemática da segurança infantil. Foi feita uma pesquisa centrada no tema, recolhendo dados disponibilizados por organizações internacionais cujo foco é a promoção da segurança das crianças. Como resultados deste pesquisa e análise documental salientamse aspetos relacionados com a promoção da parentalidade positiva, cultura de segurança e modelos de supervisão, fatores de risco e vulnerabilidade, prevenção de acidentes, segurança na internet e vigilância em saúde. Conclui-se que a segurança das crianças, bem como as estratégias a utilizar devem estar de acordo com o seu estadio de desenvolvimento. Tanto os acidentes como outras ameaças à segurança da criança, incluindo a violência, podem e devem ser prevenidos de múltiplas formas.

Palavras chave: segurança infantil; criança; acidentes não intencionais; violencia.

\section{ABSTRACT}

The child safety in general and the prevention of accidents in particular is the responsibility of all. It is important to develop a safety culture in order to minimize the risks to which children are exposed. This work intends, in one hand, to reflect on a current problem that leads to a high number of years of life lost, as well as to the reduc- 


\section{PROMOÇÃO DA SEGURANÇA NA CRIANÇA}

tion of the quality of life of many children and their relatives. On the other hand, we intend to make a reflexive analysis about the unintentional accidents being the cause of suffering, disabilities. The methodology adopted was of qualitative type, and we did a collection of documents providing data related to the problematic of children safety. A search focused on the theme was made, taking into account international organizations, which focus is the promotion of child safety. As results of this review and document analysis issues concerned with the promotion of positive parenting, culture of safety and supervisory models, factors of risk and vulnerability, unintentional injuries, safety in the internet and health surveillance were emphasized. We concluded that the safety of the children, as well as the strategies to be used must be in accordance with their stage of development. Both accidents and other threats to child safety, including violence, can and should be prevented in multiple ways.

Keywords: safety; child; accident; violence.

\section{INTRODUÇÃO}

Se por um lado o desenvolvimento é desejável, na medida em que está associado a ganhos e aquisição de competências, por outro, a criança vai estando sucessivamente exposta a mais e diferentes riscos, pela sua autonomia e pela sua curiosidade. Perante esta realidade é importante que os pais, prestadores de cuidados e educadores estejam atentos a esta realidade no sentido de se anteciparem e assim poderem proteger as crianças, pois nem sempre acontece o que diz o provérbio popular: "à criança e ao borracho põe Deus a mão por baixo".

Promover a segurança infantil, implica abordar aspetos fundamentais para a proteção da saúde da criança, entre os quais identificar situações que as coloquem em risco e pessoas que também representem rede de apoio em momentos suscetíveis (Lenz, 2008).

0 Relatório mundial para a prevenção dos acidentes com crianças, World Report on Child Injury Prevention (WHO, UNICEF, 2008), encoraja os governos e outras entidades a atuar para combater a epidemia dos acidentes com crianças e a considerar recomendações e a integra-las no desenvolvimento de programas de prevenção de acidentes com crianças.

\section{OBJETIVOS E METODOLOGIA}

Foram objetivos deste trabalho, por um lado, refletir sobre uma problemática atual que conduz a um elevado número de anos de vida perdidos, bem como à redução da qualidade de vida de muitas crianças e dos seus familiares. Por outro lado, pretendeu-se fazer uma análise reflexiva dos acidentes não intencionais como causa de sofrimento, deficiência e incapacidade.

A metodologia adotada foi de natureza qualitativa, tendo se procedido a uma recolha de documentos fornecedores de dados relativos à problemática da segurança infantil. Foi feita uma pesquisa centrada no tema, em documentos de plataformas on-line, recolhendo assim dados disponibilizados por organizações internacionais cujo foco é a promoção da segurança das crianças. Os dados recolhidos foram aqui apresentados e alvo de reflexão ou discussão.

\section{Ser criança}

A criança é razão de ser do mundo e, mais do que isso, representa o futuro do mesmo, como afirma GomesPedro (2004). Para este especialista, a criança é um ser com necessidades inalienáveis, irredutíveis, e inquestionáveis e assegurá-las é, inequivocamente, a nossa missão. 0 artigo 1 da Convenção sobre os Direitos da Criança, considera criança como todo ser humano com menos de 18 anos de idade, salvo quando, em conformidade com a lei aplicável à criança, a maioridade seja alcançada antes.

Promover a segurança da criança passa antes de mais pela salvaguarda dos seus direitos fundamentais. Esta convenção, salienta que a criança tem 0 direito a atingir 0 exponente máximo de saúde e ambiente seguro. № Artigo 24.. , alínea e) do documento, os Estados partes comprometem-se a:

"Assegurar que todos os grupos da população, nomeadamente os pais e as crianças, sejam informados, tenham acesso e sejam apoiados na utilização de conhecimentos básicos sobre a saúde e a nutrição da criança, 
as vantagens do aleitamento materno, a higiene e a salubridade do ambiente, bem como a prevenção de acidentes" (UNICEF,1989, p.18).

0 respeito da criança como sujeito de direitos próprios em várias dimensões deve ser divulgado aos pais no sentido do exercício de uma parentalidade positiva (Leandro, 2015).

De acordo com o Programa Nacional de Saúde Infantil e Juvenil (PNSIJ, 2013), o desenvolvimento psicomotor e um processo dinâmico e contínuo, defendendo, tal como Cruz (2012), que os pais, para além das funções de satisfação das necessidades mais básicas, devem proporcionar a criança um mundo físico organizado e previsível, responder as necessidades de compreensão cognitiva das realidades extrafamiliares, satisfazer as necessidades de afeto, confiança e segurança e as necessidades de interação social da criança, incluindo a sua integração na comunidade. A não satisfação das necessidades fundamentais, a ausência de fatores de proteção ou compensatórios, bem como a existência de fatores de risco com agudização dos mesmos, poderão, em determinadas circunstâncias transformar-se em situações de perigo.

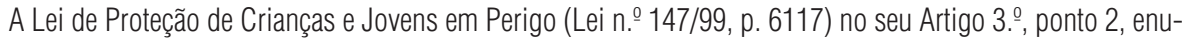
mera as situações que constituem perigo para a criança, as quais são:

a) Está abandonada ou vive entregue a si própria;

b) Sofre maus tratos físicos ou psíquicos ou é vítima de abusos sexuais;

c) Não recebe os cuidados ou a afeição adequados à sua idade e situação pessoal;

d) É obrigada a actividades ou trabalhos excessivos ou inadequados à sua idade, dignidade e situação pessoal ou prejudiciais à sua formação ou desenvolvimento;

e) Está sujeita, de forma directa ou indirecta, a comportamentos que afectem gravemente a sua segurança ou o seu equilíbrio emocional;

f) Assume comportamentos ou se entrega a actividades ou consumos que afectem gravemente a sua saúde, segurança, formação, educação ou desenvolvimento sem que os pais, o representante legal ou quem tenha a guarda de facto se lhes oponham de modo adequado a remover essa situação.

Pelo exposto se constata que não basta a existência de uma situação que afete os direitos fundamentais da criança, basta que ela se encontre desprotegida, face ao perigo. Os cuidados promotores do desenvolvimento partem da premissa de que toda a interação com a criança constitui uma experiência sensorial, que pode ser positiva ou negativa e, como tal, condicionante do desenvolvimento integral e harmonioso da criança. Promover a segurança não envolve, portanto, apena uma entidade ou uma área específica, mas implica antes uma abordagem múltipla e transversal.

\section{Promoção de uma parentalidade positiva}

Criar e educar um filho é um grande desafio para todo e qualquer casal/pai ou mãe. É exigido a estes progenitores e/ou cuidadores um conjunto de responsabilidades que visam criar condições para que um bom potencial de desenvolvimento dos seus filhos esteja assegurado.

Entende-se por parentalidade positiva como um "comportamento parental baseado no melhor interesse da criança e que assegura a satisfação das principais necessidades das crianças e a sua capacitação, sem violência, proporcionando-Ihe o reconhecimento e a orientação necessários, o que implica a fixação de limites ao seu comportamento, para possibilitar o seu pleno desenvolvimento" (CE, 2006). São Responsabilidades parentais, entre outras: Velar pela sua segurança e saúde; Prover ao seu sustento e Promover o seu desenvolvimento físico, inte-

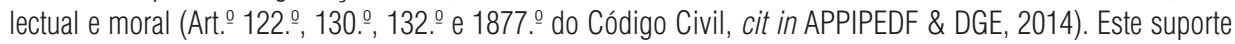
legislativo acrescenta que os filhos estão sujeitos às responsabilidades parentais até à maioridade ou emancipação.

De acordo com Conselho da Europa (CE, 2006) o melhor comportamento parental deve estar de acordo com os princípios da parentalidade positiva, que são: 


\section{PROMOÇÃO DA SEGURANÇA NA CRIANÇA}

- Sustento: responder às necessidades de amor, carinho e segurança;

- Estrutura e orientação: proporcionar a criança a sensação de segurança, rotina previsível e limites necessários;

- Reconhecimento: considerar a criança como um ser pleno de direitos, valoriza-la e ouvi-la;

- Empoderamento e autonomia;

- Educação não violenta: excluir todos os castigos corporais e psicológicos humilhantes.

Em 2008 a instituição supracitada acrescenta recomendações para promover uma parentalidade positiva. Das 8 recomendações destacamos:

- Ambiente Físico - Os pais devem promover um ambiente físico saudável e organizado, que garanta as condições de segurança e de salubridade necessárias ao desenvolvimento integral da criança, permitindo-Ihe explorar, experimentar, de maneira lúdica e agradável, cada espaço, sem riscos ou perigos para a sua saúde física e mental.

- Ambiente Emocional - Os pais devem assegurar às crianças um ambiente de apreço e reconhecimento, porque são as expressões parentais do amor e do entusiasmo que fornecem a nutrição emocional.

- Disciplina Assertiva - Os pais devem educar aplicando uma disciplina assertiva, compreensiva e compassiva, sem violência de qualquer tipo, contribuindo para um desenvolvimento e crescimento harmonioso.

\section{Cultura de segurança /modelos de supervisão}

A cultura de segurança é comummente considerada como o conjunto de crenças, valores e normas sobre segurança, partilhados pelos membros de um grupo e transmitidos através de processos de interação social. Envolve memória, reflexão e aprendizagem com vista ao desenvolvimento de sentimentos positivos que levem a encarar a segurança como responsabilidade partilhada (Evaristo, et al, s/d). De acordo com o Centers for disease Control and Prevention (CDC, S/d) as lesões não intencionais são a principal causa de fatalidades para crianças pequenas. Destes, 0 afogamento é a principal causa de morte. As Taxas de lesões cerebrais traumáticas para crianças em idade dos 0 aos 4 anos são mais altas do que as taxas para qualquer outra faixa etária e quase 0 dobro no grupo dos 15 a 24 anos (CDC, 2016). De acordo com Associação para a Promoção da Segurança Infantil (APSI, 2017), os traumatismos e lesões não intencionais, ou acidentes, constituem ainda uma importante causa de morte nas crianças e jovens que vivem em Portugal, sendo a maior causa de morte a partir dos 5 anos. Segundo esta organização, as mortes são apenas a "ponta do iceberg" já que por cada criança que morre, muitas dezenas são internadas e centenas são assistidas nos serviços de saúde.

A Diretora-Geral da Organização Mundial de Saúde (2008) e Diretora Executiva da UNICEF (2008) salientam no prefácio do Relatório Mundial para a prevenção dos acidentes com crianças o que "implementação de intervenções, já avaliadas, de prevenção de acidentes com crianças pode salvar mais de uma centena de vidas por dia" (p.VII). 0 desenvolvimento de uma cultura cívica de segurança não se esgota nas escolas, embora elas constituam espaços educativos favoráveis à reflexão e aplicação de princípios fundamentais da convivência coletiva nas sociedades democráticas, contribuindo para um ambiente adequado à aprendizagem (Direcção-Geral de Inovação e de Desenvolvimento Curricular, s/d).

0 Relatório Mundial para a prevenção dos acidentes com crianças (World Report on Child Injury Prevention, 2008) encoraja os governos e outras entidades a combater a epidemia dos acidentes com crianças e faz, entre outras, as seguintes recomendações:

Integrar os acidentes com crianças numa abordagem compreensiva da saúde e do desenvolvimento infantil; Implementar políticas e planos de ação de prevenção dos acidentes com crianças;

Implementar ações específicas de prevenção e controlo dos acidentes com crianças;

Reforçar os sistemas de saúde para combater os acidentes com crianças (WHO, 2008).

Face à gravidade das situações associadas aos riscos e comportamentos, vulnerabilidade da criança face à (inter)dependência dos demais, as crianças requerem modelos de supervisão diferentes. Estes modelos, têm de 
estar focados: a) na supervisão em função da idade, exposição e risco; b) na proximidade física do supervisor da criança, tendo em conta as caraterísticas da criança e seu estádio de desenvolvimento; c) no grau de envolvimento verbal e físico da criança; e d) no tempo que o supervisor está a vigiar ativamente (WHO, 2008). Uma educação para a prevenção e autoproteção na opinião de Evaristo (s/d), deve reforçar a autoconfiança, a consciência das responsabilidades inerentes ao exercício dos direitos e enfatizar, por outro lado, a importância das relações de solidariedade na escola e de parceria na comunidade.

\section{Fatores de risco e de vulnerabilidade para acidentes}

Os fatores de risco e de vulnerabilidade para a ocorrência de acidentes (lesões acidentais não intencionais), são divididos em: (1) intrapessoais, que são relacionados com a idade, ao sexo e o comportamento de risco, sendo este último atribuído a adolescentes; (2) interpessoais, que são relacionados com os cuidados exercidos pela família e no ambiente doméstico; (3) institucionais, que são relacionados com a comunidade, o bairro, a escola e a urbanização; e (4) fatores culturais, que são aqueles ligados à sociedade (Baker; Runyan, 2012).

Tendo presente os fatores de risco e de vulnerabilidade descritos anteriormente urge ter uma atenção especial aos contextos. A casa / lar, que por definição deveria ser um lugar mais seguro, pode e é na maioria dos casos, ser um contexto perigoso, caso não exista uma atitude antecipatória face à aquisição de competências em função do desenvolvimento psicomotor, ou seja uma prevenção primária.

Para o World Report on Child Injury Prevention (2008) atuar, implica incluir as crianças nos processos de decisão, envolvendo-as em programas de prevenção bem como: ter um papel de modelo, adotando medidas de segurança para reduzir os riscos de acidentes, como por exemplo o uso de equipamentos de proteção, bem como levar as crianças a brincar em locais seguros; promover a prevenção de acidentes com as pessoas e na família; evitar comportamentos de alto risco.

Também a APSI (2017) reforça a importância de três aspetos: "Conhecer os riscos" obtendo informação (estatística), mas também ter conhecimento relacionado com as necessidades de formação académica e profissional, bem como de educação cívica; "Criar ambientes seguros" devendo abranger os diversos ambientes que as crianças frequentam diariamente (rodoviário, casa, escola, ...) , nos quais deverão ter a oportunidade de se movimentarem com autonomia, sem riscos inaceitáveis criados pelo ambiente e, por último, "minimizar os acidentes" reduzindo 0 impacto das lesões não intencionais, nomeadamente ao nível da mortalidade, morbilidade e incapacidades relacionadas com os mesmos, sendo importante não só diminuir o número de acidentes, mas também a gravidade das suas consequências, ou seja atuar ao nível da prevenção secundária e terciária.

\section{Prevenção de acidentes}

A palavra "acidente" é tradicionalmente usada para definir a ocorrência de eventos que resultem em uma lesão. Por ser mais abrangente, considera as categorias: "intencional" e "não intencional", sendo que a categoria "intencional" pode ser subdividida em violência "interpessoal" e "Auto provocada". Entretanto, tal distinção entre acidente e lesão em termos de causa e efeito é motivo de confusão, pois não é a lesão em si que é intencional ou não intencional, mas sim 0 ato do qual decorre da lesão. A OMS define um acidente como algo que resultou ou poderia ter resultado em uma lesão. Contudo, a palavra "acidente" carrega uma conotação de imprevisibilidade ou casualidade, levando a crer que seja incontrolável ou não prevenível. No entanto, os acidentes podem ocorrer nos vários contextos ou itinerários em que a criança se movimenta, sendo em cada um contexto um sujeito com funções diferentes, como se segue.

\section{Enquanto peão}

A aprendizagem da criança processa-se muito por imitação. Assim, bem cedo a criança deve ser ensinada ou preparada para quando anda a pé, a deslocar-se pelos passeios e bermas no sentido mais seguro; a caminhar o mais longe possivel da faixa de rodagem; caminhar pelo lado esquerdo e de frente para os veiculos numa rua ou estrada sem passeios; a atravessar sempre na passadeira; a respeitar a sinalização; a usar objetos que emitam 


\section{PROMOÇÃO DA SEGURANÇA NA CRIANÇA}

luz a noite (roupas claras ou colete de segurança, mochila com bandas de tecido refletor) e a escolher locais bem iluminados para atravessar.

\section{Enquanto Passageiro}

Ao viajar, a criança deve ser transportada sempre no banco traseiro do automóvel; usando sempre o cinto de segurança e equipamento específico, como cadeirinha, adequados ao seu tamanho e idade. Neste contexto, deve ser instruída a entrar e sair do carro pela porta do lado do passeio; a nao tentar abrir as portas com o carro em andamento; a não atirar objetos pela janela; e a nao colocar a cabeça ou alguma parte do corpo de fora do carro em movimento.

\section{Enquanto ciclista}

A criança tem de usar capacete sempre que se movimenta de bicicleta. Deve circular o mais a direita possível da faixa de rodagem e quando ha mais do que uma bicicleta em grupo, deve circular em fila e não em paralelo. Ao mudar de direção a criança deve aprender a estender o braço na direção para a qual deseja virar.

\section{Nos itinerários}

Quer seja como peão, como ciclista ou como ocupante de um automóvel, é fundamental capacitar a criança para não falar com estranhos, assim como ajudá-la a perceber que é perigoso aceitar boleias de desconhecidos. Positivamente, deve ser aconselhada a andar em grupo e aprender e que no caso de se perder deverá dirigir-se a uma pessoa adulta confiável e responsável, nomeadamente agentes de autoridade identificados por farda ou com placa de identificação.

Quando a criança brinca, os seus cuidadores devem escolher um local seguro - um parque infantil ou um espaço sem trânsito automóvel. A criança deve aprender a brincar de preferência em grupo; a não brincar as escondidas em locais públicos; a proteger-se de lesões físicas usando equipamentos adequados para as atividades em que se envolve, nomeadamente capacete, cotoveleiras, joelheiras, luvas e calçado adequado, bicicleta, skate ou patins.

\section{Prevenção da violência}

A Organização Mundial de Saúde define Violência como "o uso intencional de força física ou poder, real ou como ameaça contra si próprio, outra pessoa, um grupo ou uma comunidade, que resulte ou tem grande probabilidade de resultar em ferimentos, morte, danos psicológicos, desenvolvimento prejudicado ou privação." (OMS, 2014, p. 2)

A violência visa sempre ferir ou coagir o outro, física ou psicologicamente, a fim de lhe causar prejuízo. Pode assumir a forma de discriminação quando tem por base estereótipos (culturais, físicos, etários, étnicos, de género...), ou seja, representações negativas e deturpadas das diferenças (Evaristo et al., s/d).

Tal como definido, pelo muitas vezes observado, constata-se que a violência pode ter graves consequências e causar danos no desenvolvimento psicoafetivo do ser humano. No caso particular das crianças, estas podem ser consideradas vítimas de violência doméstica como (APAV, 2012):

- Testemunhas de violência doméstica, o que inclui presenciar ou ouvir os abusos infligidos sobre uma vítima, ver os sinais físicos depois de episódios de violência ou testemunhar as consequências desta violência na pessoa abusada;

- Instrumentos de abuso, na medida em que um pai, uma mãe agressor, ou outro cuidador pode utilizar os filhos ou crianças a seu cuidado como uma forma ou objeto de abuso e controlo;

- Vítimas de abuso, podendo ser física e/ou emocionalmente abusadas por um/a agressor/a, ou mesmo, nalguns casos, pela própria vítima.

0 Relatório Mundial sobre a Prevenção da Violência (OMS, 2014) integrou diversos objetivos de prevenção da violência na agenda de desenvolvimento pós-2015, um dos quais foi reduzir em 50\% as mortes relacionadas 
com a violência em todos os lugares do mundo, e eliminar a violência contra a criança e todas as formas de violência contra mulheres e meninas até 2030.

0 mesmo relatório considera a violência interpessoal como um fator de risco para problemas sociais e de saúde, que podem perdurar ao longo de toda a vida. Pode ocorrer entre membros de uma família, parceiros íntimos, amigos, conhecidos e estranhos. As formas de violência incluem maus-tratos à criança, violência juvenil, violência praticada por parceiro íntimo, violência sexual e abuso de idosos. A OMS (2014), recorrendo a vários estudos científicos, afirma que a violência é prevenível e identifica estratégias de prevenção, com potencial para reduzir a ocorrência de múltiplas formas de violência, as quais podem ajudar a reduzir a probabilidade de que indivíduos perpetrem violência ou se tornem vítimas. Essas estratégias são: desenvolver relacionamentos seguros, estáveis e protetores entre crianças e seus progenitores e cuidadores; desenvolver em crianças e adolescentes competências para a vida; diminuição dos consumos, promover a igualdade de género e mudar normas culturais e sociais que apoiem a violência.

Há cada vez mais o reconhecimento por diversos organismos de que a violência é um verdadeiro problema de saúde pública. 0 suporte legislativo punitivo para 0 agressor e protetor da vítima é cada vez mais uma preocupação. "Leis contra a violência enviam uma mensagem clara à sociedade sobre comportamentos inaceitáveis, e legitimam as ações necessárias para garantir a segurança da população em todos os momentos" (OMS, 2014, p. 38).

\section{Segurança na internet}

A internet é hoje, sem qualquer dúvida, a via mais rápida de estabelecer comunicações, onde a partilha de imagens de crianças nas redes sociais se tem tornado muito comum. Em 2010, por exemplo, uma pesquisa realizada entre pais de oito países revelou que $81 \%$ das crianças de dois anos já têm algum tipo de pegada digital devido às atividades on-line dos pais. (Better Internet for Kids, 2019). Sobre este assunto, a plataforma cita Andra Siibak, professora na Universidade de Tartu a qual afirma que a a identificação de dados da infância e da vida das crianças começa mesmo antes de elas nascerem. Hoje, não é raro os novos pais comunicarem as boas notícias de expectativa a amigos e conhecidos através dos meios de comunicação social, partilhando logo imagens de ecografias. A autora refere também que a partilha de fotos de crianças pequenas se tornou uma norma social na era digital inerente à paternidade. Os pais, os pares e a escola, são importantes fontes de mediação do uso da internet por crianças e adolescentes.

A forma como os pais procuram regular o uso da internet pode ser classsificada em duas macrocategorias (Livingstone et al., 2017): a mediação de tipo capacitante, que inclui todas as formas de mediação ativa do uso da internet e da segurança online (ou seja, a forma que sugere um uso positivo da tecnologia); e a mediação de tipo restritivo que condiciona o tempo passado online ou interdita atividades e plataformas, fazendo ainda uso de software de controlo parental ou de outros filtros. Face a esta realidade os autores defendem que podem ser configuradas regras informais de atuação no ciberespaço, as quais podem ser acordadas entre pais e filhos, nomeadamente: 0 números de horas, (tempo) por dia/semana para entretenimento (jogos, consulta de sítios, redes sociais); a senha das redes sociais ser do conhecimento dos pais, mas nunca dos amigos; pedir aos pais para serem eles a efetuar compras online; informar os pais sempre que for abordado(a) de forma inapropriada por alguém (palavrões, convites, conversas íntimas, fotografias ou imagens de conteúdo sexual) ou se sentir incomodado(a) com alguma coisa; nunca divulgar dados pessoais como endereço, número de telefone/telemóvel, escola e locais que frequenta, senha de acesso a algum serviço da net; só colocar fotografias autorizadas pelos pais; e ainda salientar a importância de respeitar os outros e não fazer comentários depreciativos sobre ninguém.

Um estudo de 2010 citado na plataforma Better Internet for Kids (2019), mostrou que a exposição a riscos não produz necessariamente danos. Outro estudo de 2014, referido na mesma plataforma, procurou identificar mudanças trazidas pelos novos meios de comunicação móvel. Os resultados em sete países, mostraram que a correlação "mais oportunidades, mais riscos" não ocorria do mesmo modo. Por exemplo na Itália, Dinamarca e Roménia a maior incorporação da internet nas atividades quotidianas levou a um alargamento das oportunidades 


\section{PROMOÇÃO DA SEGURANÇA NA CRIANÇA}

e também a uma maior exposição a riscos. Pelo contrário, na Bélgica e, em menor escala, em Portugal e no Reino Unido, 0 alargamento das oportunidades não conduziu a maior exposição a riscos (EU Kids Online Portugal, 2019).

0 espaço digital, apesar de comportar alguns riscos, continua a garantir que as crianças tenham acesso a experiências on-line positivas de alta qualidade desde tenra idade, podendo ajudá-las e capacitá-las a se tornarem cidadãos ativos e participativos, desde que o conteúdo online seja usado de modo positivo. Na plataforma Better Internet for Kids (2019) é definido conteúdo online positivo todo o conteúdo digital destinado às crianças, que Ihes permite aprender, divertir-se, criar, desfrutar, desenvolver uma visão positiva de si mesmas e respeitar a sua identidade, aprimorar a sua participação na sociedade e produzir e distribuir seu próprio conteúdo positivo.

\section{Vigilância em saúde}

A segurança de crianças e jovens passa também por uma adequada vigilância em termos de saúde, pois esta promove a deteção de sinais precoces de lesões intencionais e não intencionais. Os profissionais de saúde têm a oportunidade tanto de capacitar os cuidadores na satisfação das necessidades humanas básicas como de encaminhar situações suspeitas merecedoras de preservar os direitos da criança.

Neste domínio, a segurança passa também pela imunização adequada em função das patologias preveníveis através do processo de vacinação, conforme estipulado para cada país, ou seja, no seu Plano Nacional de Vacinação (PNV). Este plano vai mudando à medida que novos agentes causadores de doença surgem no ambiente e põem em risco a saúde da criança e daqueles com quem convive. Apesar de alguns movimentos de contestação e oposição à vacinação a que temos assistido atualmente pelos meios de comunicação social, não temos dúvidas de que a vacinação é sem dúvida um fator de proteção e segurança para a criança, que ainda débil se está a expor a um conjunto de antigénios que Ihe podem causar doença e ameaçar a vida. Portanto, assegurar a vacinação é uma medida de elevada segurança para a saúde.

\section{CONCLUSÃO}

Neste texto reunimos pesquisas de várias fontes internacionais, sobre diversos temas que confluem para a temática da segurança da criança. Quer em casa, quer na rua ou escola, ou até noutro espaço comunitário em que a criança participe, há sempre faatores de risco para a sua segurança. A educação tem de apostar sobretudo no desenvolvimento de competências pessoais e sociais para enfrentar e lidar positivamente com os perigos, que 0 mesmo é dizer capacitar a criança desde cedo para se ancorar no seu porto seguro, mesmo que esteja rodeada de adultos cuidadores responsáveis e confiáveis.

\section{REFERÊNCIAS BIBLIOGRÁFICAS}

APAV (2012) .Violência doméstica. [Acesso: https://apav.pt/vd/index.php/features2]

APPIPEDF \& DGE (2014). Guia para os estabelecimentos de ensino, pais, mães e encarregados de educação.

Lisboa: DGE, MEC [Acesso: https://www.dge.mec.pt/sites/default/files/ficheiros/guia_ parental_fev2014_net.pdf]

APSI (2017). 25 anos de segurança infantil em Portugal, relatório de avaliação 2017 disponívelem :http://www.apsi.org.pt/images/25anos/PDF/APSI_RELATORIO_SEGURANCA_INFANTIL_2017.pdf

Baker, S. P.; Runyan, C. W. (2012). William Haddon, Jr., his legacy. Disponível em: <http://www.iprc. unc.edu/pages/training/p1.ppt>.

Better internet for kids (2019). Enfrentando os desafios da parentalidade digital na era do big data, disponível em https://www.betterinternetforkids.eu/web/portal/practice/awareness/detail?articleld=4935921

Better internet for kids (2019). Positive Online Content Campaign, disponível em: https://www.betterinternetforkids.eu/web/positiveonlinecontent/about

Blum-Ross, A., \& Livingstone, S. (2017). "Sharenting," parent blogging, and the boundaries of the digital self. Popular Communication, 15(2), 110-125. 
Brasil (2012)., Saúde da criança : crescimento e desenvolvimento / Ministério da Saúde. Secretaria de Atenção à Saúde. Brasília: Ministério da Saúde, Departamento de Atenção Básica.

Centers for Disease Control and Prevention. (2016). Rates of TBI-related emergency department visits by age group-United States, 2001- 2010. Retrieved from https://www.cdc.gov/traumaticbraininjury/data/rates _ed_byage.html

Centers for Disease Control and Prevention, National Center for Injury Prevention and Control. (N.d.). 10 leading causes of death by age group United States-2016 disponivel em https://www.cdc.gov/injury/ wisqars/pdf/leading_causes_of_death_by_age_group_2016-508.pdf

CNPDPCJ (2019). Conceito de Risco/Conceito de Perigo disponível em https://www.cnpdpcj.gov.pt/materiaisdiversos/a-crianca-em-risco/conceito-de riscoperigo.aspx

Conselho da Europa (2006). Construir uma Europa com e para as crianças. Brochura.

Council of Europe (2008). Parenting in Contemporary Europe. A positive approach. Strasbourg. Council of Europe Publishing.

Cruz, 0. (2005). Parentalidade. 1a ed. Coimbra: Quarteto, atraves de estadios, com uma ordem constante de aparecimento das diferentes funcoes, com surgimento variavel dependente da individualidade de cada crianca.

DGE, (2014). Guia para os estabelecimentos de ensino, pais, mães e encarregados de educaçãofile:///C:/Users/User/Downloads/i008760.pdf

Direcção-Geral de Inovação e de Desenvolvimento Curricular, S/d), disponível em:http://www.dgs.pt/em-destaque/paginas-de-sistema/saude-de-a-a-z/prevencao-de-acidentes-com-criancas-e-jovens.aspx

DGS (2016). Prevenção de Acidentes com Crianças e Jovens disponível em: https://www.dgs.pt/emdestaque/paginas-de-sistema/saude-de-a-a-z/prevencao-de-acidentes-com-criancas-e-jovens.aspx

Evaristo, T., Oliveira, I., Vaz, E., Sales, F., Carvalho, I., Nunes, L. \& Parente, L.(s/d). Cidadania e segurança. Lisboa: Ministério da Educação, Direcção-Geral de Inovação e Desenvolvimento Curricular. [Acesso: http://www.dge.mec.pt/sites/default/files/ficheiros/cidadaniaeseguranca.pdf]

EU Kids Online Portugal (2019). Usos, competências, riscos e mediações da internet reportados por crianças e jovens (9 -17 anos) disponível em: file:///C:/Users/User/Downloads/i008763.pdf

Gomes-Pedro (2004). 0 que é ser criança? Da genética ao comportamento, Análise Psicológica (2004), 1 : 3342

Leaver, T. (2017). Intimate Surveillance: Normalizing Parental Monitoring and Mediation of Infants Online. Social Media+ Society, 3(2).

Livingstone, S. Third, A. (2017). Children and young people's rights in the digital age: An emerging agenda, disponível em : https://journals.sagepub.com/doi/10.1177/1461444816686318

Mascheroni, G. \& Holloway, D. (2019). The quantified child: Discourses and practices of data veillance in different life stages. In Erstad, O., Flewitt, R., KummerlingMeibauer, B. and Pires Pereira. I. (Eds.) The Routledge Handbook of Digital Literacies in Early Childhood.

OMS (2014). Relatório Mundial Sobre a Prevenção da Violência 2014. São Paulo: Núcleo de Estudos da Violência da Universidade de São Paulo 2015 (Tradução para Português).

UNICEF (1989). Convenção sobre os Direitos da Criança, disponível em: http://www.unicef.pt/docs/pdf_publicacoes/convencao_direitos_crianca2004.pdf.

WHO (2008). World report on child injury prevention disponível em:

https://books.google.pt/books?id=UeXwoNh8sbwC\&printsec=frontcover\&hl=pt-PT\#v=0nepage\&q\&f=true 
